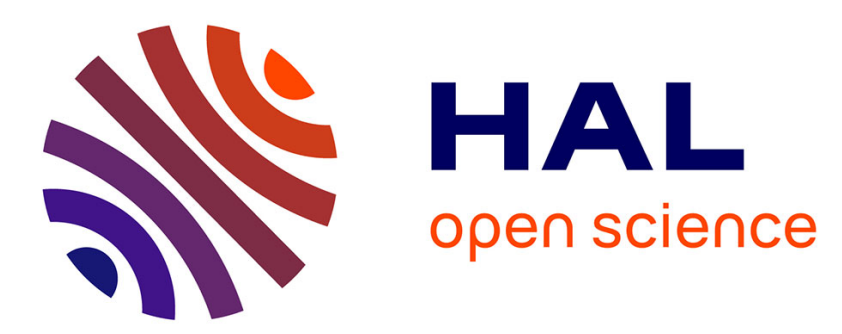

\title{
Numerical simulation and PIV experimental analysis of electrohydrodynamic plumes induced by a blade electrode
}

\author{
Ph Traoré, M Daaboul, Ch Louste
}

\section{- To cite this version:}

Ph Traoré, M Daaboul, Ch Louste. Numerical simulation and PIV experimental analysis of electrohydrodynamic plumes induced by a blade electrode. Journal of Physics D: Applied Physics, 2010, 43 (22), pp.225502. 10.1088/0022-3727/43/22/225502 . hal-00569621

\section{HAL Id: hal-00569621 \\ https://hal.science/hal-00569621}

Submitted on 25 Feb 2011

HAL is a multi-disciplinary open access archive for the deposit and dissemination of scientific research documents, whether they are published or not. The documents may come from teaching and research institutions in France or abroad, or from public or private research centers.
L'archive ouverte pluridisciplinaire HAL, est destinée au dépôt et à la diffusion de documents scientifiques de niveau recherche, publiés ou non, émanant des établissements d'enseignement et de recherche français ou étrangers, des laboratoires publics ou privés. 


\title{
Numerical simulation and PIV experimental analysis of electrohydrodynamic plumes induced by a blade electrode.
}

\author{
Ph Traoré \\ Laboratoire d'Etudes Aérodynamiques \\ Boulevard Pierre et Marie Curie, BP 30179, \\ 86962 Futuroscope-Chasseneuil, France \\ philippe.traore@univ-poitiers.fr
}

\author{
M Daaboul \\ Laboratoire d'Etudes Aérodynamiques \\ Boulevard Pierre et Marie Curie, BP 30179 , \\ 86962 Futuroscope-Chasseneuil, France
}

\section{Ch Louste}

Laboratoire d'Etudes Aérodynamiques

Boulevard Pierre et Marie Curie, BP 30179,

86962 Futuroscope-Chasseneuil, France

\begin{abstract}
In this paper, a comparative study between numerical and experimental results from PIV measurements is presented in the case of two-dimensional electrohydrodynamic plumes that arise when a sharp metallic blade, submerged in non conducting liquids, supports high electric potential. Experiments and numerical simulations have been conducted in order to confront the both approaches. A very good agreement has been found through velocity profiles and velocity fields which testifies the relevance of our numerical model. For high potentials the jet flow issued forth from the blade becomes unsteady and starts to flap on the vertical wall. Some captions of the temporal evolution of the isocontours of charge density which is not accessible from experiment are presented thanks to the numerical simulation.
\end{abstract}

\section{Introduction}

Performance of industrial systems working with liquids could be improved by using well adapted flow control devices. For instance electrohydrodynamic (EHD) devices could provide an efficient solution to control a given flow. In fact EHD apparatuses have many advantages such as: low power consumption, short response time, and good reliability. They are less subjected to failures of any kind than pure mechanical devices also utilized for flow control and they can be completely non-intrusive.

In electrohydrodynamics, the Coulomb force is the main efficient force to induce the liquid motion. In absence of thermal gradient, only two different phenomena can produce a volume charge density and then a Coulomb force. 
The first one is the so-called charge injection process and is associated to unipolar injection of ions at a metal/liquid interface [1]. The second one is the conduction pumping phenomena which is based on the process of dissociation and recombination of electrolytic species. Atten \& Seyed-Yagoobi [2] have demonstrated that in absence of injection this dissociation-recombination process results in the production of heterocharge layers of finite thickness in the vicinity of the electrodes. They also predict that the use of asymmetric electrodes could induce a net liquid motion. This model has been experimentally and numerically proved by Feng and Seyed-Yagoobi [3]. Many devices and applications based on these two phenomena have been developed. Most of them are EHD pumps or thin film devices for cooling applications. A scientific overview of numerical and experimental research on the conduction model could be found in [4]. Although, the conduction phenomenon is better adapted for pumping applications, injection remains interesting because it induce a stronger Coulomb force. In this article, a typical blade-plane set up is used to induces ions injection in a dielectric liquid [5][6]. In such conditions, convective motion of a jet shape arises. These particular flows have been referred to as EHD plumes and are present in most of industrial devices exploiting electric forces.

In previous works it has been shown that a blade-plane geometry device generates an impinging jet which can reach a velocity of $1 \mathrm{~m} / \mathrm{s}$ [7][8].

The adaptation of the Particle Image Velocimetry (PIV) technique to electrohydrodynamic flows [9] has permitted to obtain large velocity maps of jets. Characteristics of such flows have been studied as well as in transient or in stationary regimes [9][10]. Although the last improvements of the PIV measurement technique some data remain non-measurable.

The analogy of EHD plumes with thermal ones has conducted many authors [11][12][13][14][15] to analyze EHD plumes by the mean of self-similar analysis or integral model. Under some simplifying assumptions the governing EHD equations are made tractable and the mathematical model is close to the one of thermal plumes for $\operatorname{Pr} \rightarrow \infty$ (where $\operatorname{Pr}=v / \alpha$ is the Prandtl number $v$ is the kinematic viscosity of the fluid and $\alpha$ its thermal diffusivity). Another way to obtain information on data which are not accessible experimentally, for instance the electric charge density in the device as well as the electric field at every location of space, is to require to numerical simulations. Several attempts to model numerically the development of EHD flows and especially electro-convective flows have been made in the past. But most of the authors started their computations from an assumed velocity field and not from a real resolution of the Navier-Stokes equations [15]. In [16] the appropriate electrodynamics equations coupled with the full Navier-Stokes equations are solved numerically with the help of an efficient finite volume method to study the flow structure of EHD plumes.

In this paper, detailed comparisons between experimental results obtained from PIV measurements and numerical predictions are presented in the case of an EHD plume induced by charge injection from a blade. Velocity profiles and vector fields are correlated and the charge field in the device is extracted from the numerical results. 


\section{Experimental apparatus and techniques}

\subsection{Electrical Device}

A schematic diagram of the system is shown in figure. 1 . The test cell is composed of a $30 \mathrm{~cm} \times 15 \mathrm{~cm} \times 15 \mathrm{~cm}$ glass aquarium filled with the dielectric liquid. The electrical device is totally immerged in the liquid and fixed in a confined zone of $10 \mathrm{~cm} \times 8 \mathrm{~cm} \times 6 \mathrm{~cm}$ with flat glass surfaces in order to be able to realize PIV measurements without Laser reflections. An $8 \mathrm{~cm}$ long and $0.5 \mathrm{~mm}$ thick stainless steel blade is placed in front of a duralumin flat plane electrode. The distance $d$ between the blade tip and the counter-electrode is set to $20 \mathrm{~mm}$ and the radius of curvature of the blade tip is about $7 \pm 2 \mu \mathrm{m}$.

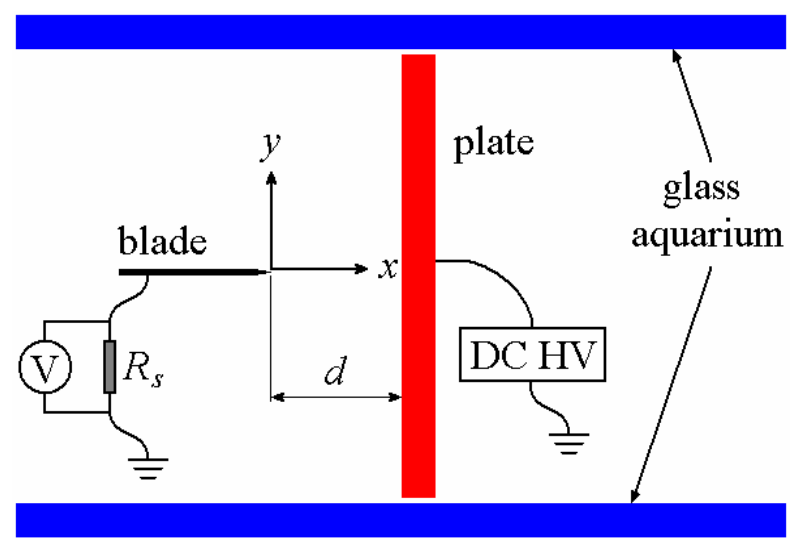

Figure 1. Experimental apparatus

A variable difference of potential $(0-60 \mathrm{kV})$ is supplied by a Spellman SL1200 DC power supply. A Meterman $37 \mathrm{XR}$ multimeter $( \pm 0.1 \mathrm{~V}- \pm 0.01 \mathrm{~mA})$ was used to measure the voltage across a shunt resistance $\mathrm{Rs}=99.3 \mathrm{k} \Omega$.

The liquid used in the experiments is dielectric oil with slight electrical conductivity. The characteristics of this dielectric liquid at a temperature of $20^{\circ} \mathrm{C}$ are presented in Table I.

Table 1. Typical Characteristics of the Dielectric Oil at $20^{\circ} \mathrm{C}$

\begin{tabular}{lll}
\hline Mass density & $\rho\left(\mathrm{kg} / \mathrm{m}^{3}\right)$ & 850 \\
Kinematic viscosity & $v\left(\mathrm{~m}^{2} / \mathrm{s}\right)$ & $4.310^{-6}$ \\
Electrical conductivity & $\sigma(\mathrm{S} / \mathrm{m})$ & $1.1510^{-9}$ \\
Relative permittivity & $\varepsilon_{\mathrm{r}}$ & 2.2 \\
Ionic mobility & $\mathrm{m}^{2} /(\mathrm{V} . \mathrm{s})$ & $10^{-8}$ \\
\hline
\end{tabular}




\subsection{Particle Image Velocimetry Method}

The Particle Image Velocimetry method is a common technique used in experimental fluid dynamics. It consists of seeding a flow with small tracer particles and tracking these particles to determine the velocity map of the test zone. A double pulsed laser sheet illuminates the investigation scene and a CCD camera takes 2 successive photos in order to determine the successive positions of the seeding particles (figure. 2). Special software using a correlation algorithm gives the velocity map knowing the time delay between the 2 successive images.

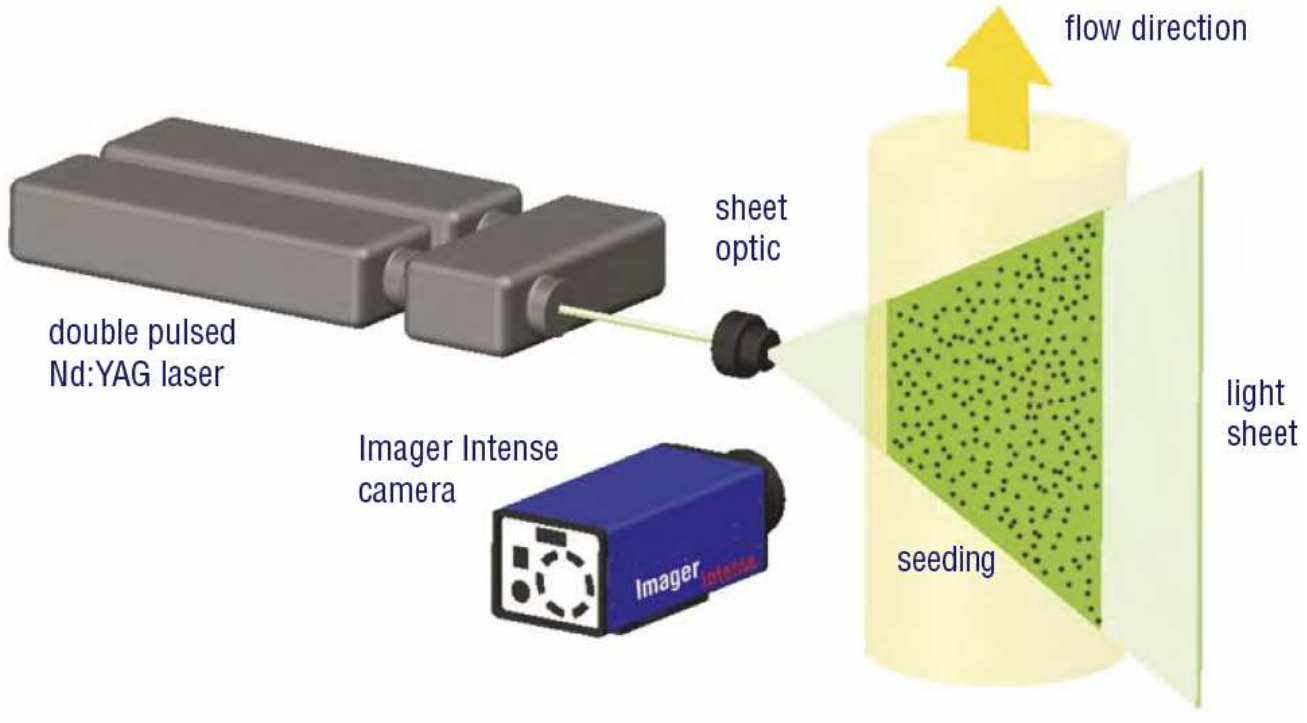

Figure 2. Particle Image Velocimetry measurement system (@ LaVision GmbH, Germany, http://www.lavision.de).

This work was realized with a LaVision acquisition system (LaVision GmbH, Göttingen, Germany.) The images were acquired with a CCD digital camera at a spatial resolution of $1376 \times 1040$ pixels. The frames were analyzed with Davis 7.1 software. The choice of seeding particles is essential particularly in an EHD context. Addition of particles in an EHD flow has been widely studied in the context of electrostatic precipitators and essentially in air [17][18][19][20]. However in the case of liquids the phenomenology is rather different because of the presence of the electrical double layer at the particle surface, the liquid conductivity and its relative permittivity. Thus the behaviour of these particles in air will be different compared to the behaviour they would have in liquids. In air electrostatic precipitators, the electrostatic charge of particles could be important and thus their trajectories would be essentially driven by the electric field and only slightly affected by the air flow itself. In the case of liquids, and particularly in PIV measurements the goal sought after would be precisely that solid particles follow the trajectories of the fluid particles [21]. In order to achieve such goal and to avoid that the solid particles have their own trajectories completely driven by the electric field and roughly independently of the fluid flow, some requirements must be met. In such case it is precisely important to avoid the electrostatic precipitation of the particles on the 
electrodes and the charge accumulation which could modify, firstly the hydrodynamic trajectories of these particles due to the electric field and secondly the electric field itself. Daaboul [21], have demonstrated that the use of $\mathrm{SiO}_{2}$ particles of $0.5 \mu \mathrm{m}$ diameter with a concentration of less than $100 \mathrm{mg} / \mathrm{l}$ must be employed to have satisfactory results. In fact, with such a concentration, the electric current is not modified. Daaboul has proven that the global shape of the charged plume as well as the jet velocity profiles are not affected for these low concentrations. In this work we have used these particles with a $20 \mathrm{mg} / \mathrm{l}$ concentration.

\section{Numerical method}

The problem is formulated considering the usual hypotheses of a Newtonian and incompressible fluid of dynamic viscosity $\mu$ and density $\rho$. The Navier-Stokes equations (mass and momentum conservation) are coupled with EHD equations and give rise to the following partial differential equations system.

$$
\begin{aligned}
& \nabla \cdot \vec{U}=0 \\
& \rho\left(\frac{\partial \vec{U}}{\partial t}+(\vec{U} \cdot \nabla) \vec{U}\right)=-\nabla P+\mu \Delta \vec{U}+q \vec{E} \\
& \frac{\partial q}{\partial t}+\nabla \cdot(q(\vec{U}+K \vec{E}))=0 \\
& \Delta V=-\frac{q}{\varepsilon} \\
& \vec{E}=-\nabla V
\end{aligned}
$$

$\vec{U}$ is the fluid velocity, $P$ the pressure, $q$ the charge density, $V$ the potential and $\vec{E}$ the electric field. $K$ is the ionic mobility and $\varepsilon$ is the dielectric constant. In the charge density transport equation (3), diffusion term has not been included since it is negligible compared to the migration term [22]. The injection of unipolar charge of mobility $K$ from the blade is assumed homogeneous and autonomous [23][24]; this mean that the charge density at the blade is supposed to be constant and equal to $q_{0}$ at all times since the injector and hence the injection rate are not influenced by perturbation in the bulk. We have depicted the computational domain and the boundary conditions in figure $3 . q_{0}$ and $V_{0}$ are respectively the charge density and potential applied on the blade. 


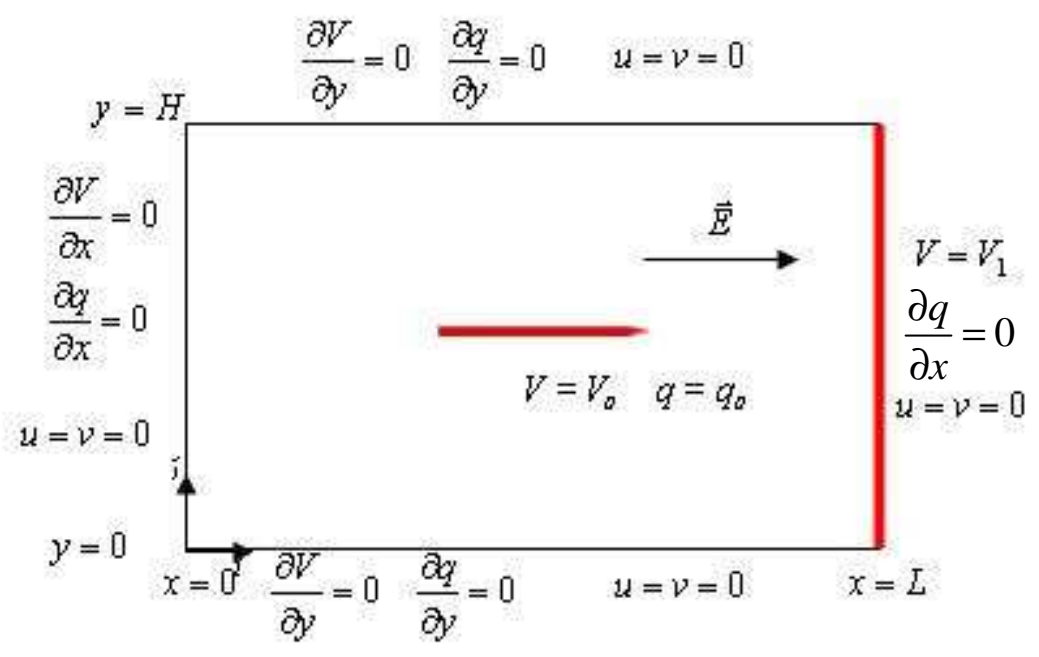

Figure 3. Computational domain and boundary conditions

The numerical procedure is based on the integration of the whole system of equations by a finite volume method using a staggered grid and a semi-implicit second order in time and space accurate schemes [25]. All details of the present numerical method can be found in [16].

\section{Results and discussion}

The applied voltage between the blade and the plate counter electrode induces a very strong electric field at the blade tip. It is well known that in this configuration the measured current can be decomposed into a conduction current part and an injected current one which originates from the unipolar injection of charges at the blade tip. On figure 3 we have presented the current-voltage characteristic from experiments. It shows a typical behaviour associated with a space charge limited condition [26] .

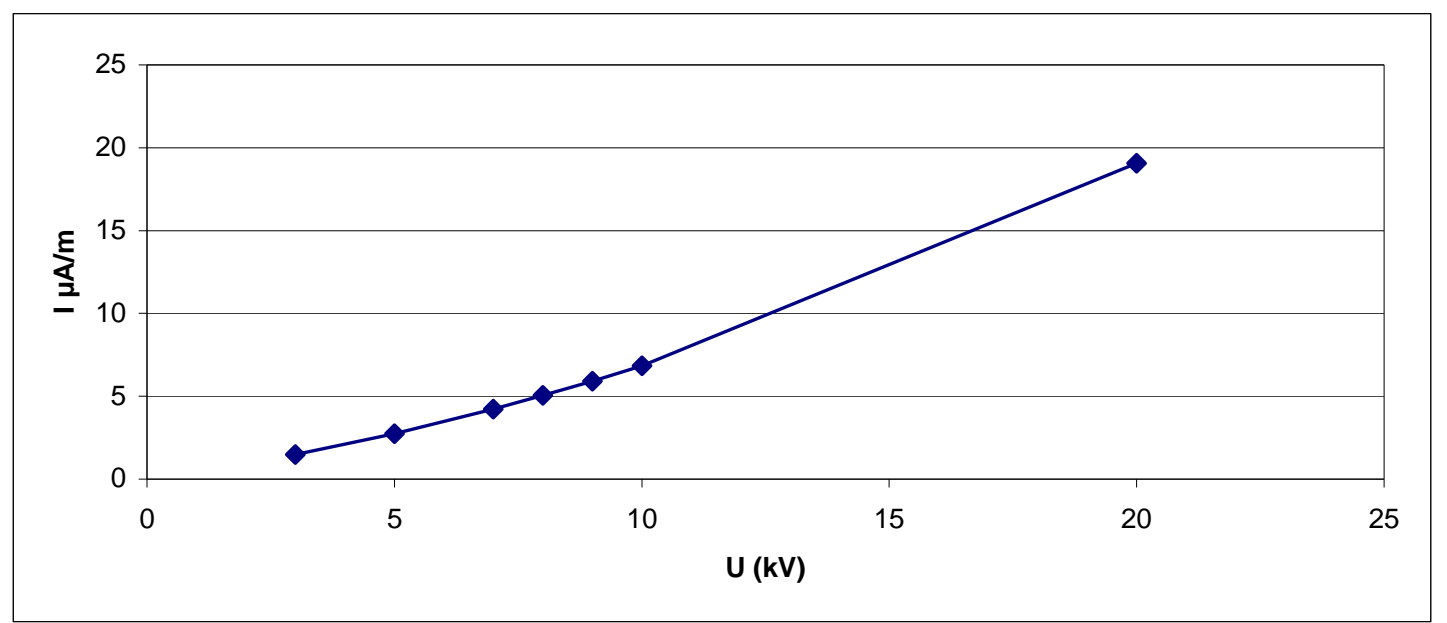


Figure 4. Experimental current-voltage characteristic in blade-plate geometry.

The structure of the flow is composed of two main vortices on either side of the plumes which are easily identified on the figure 5 which represents the velocity field and isocontours of the velocity magnitude. For the case $-5 \mathrm{kV}$ we obtain a stationary laminar regime while the $-20 \mathrm{kV}$ one is fully unsteady and turbulent. In that case, the captions represent the temporal mean over all discrete times of the simulation, and over 1000 instantaneous velocity fields issued from recorded PIV images for the experiment. The comparison between experimental and numerical results shows a very good agreement.

$-5 \mathrm{kV}$

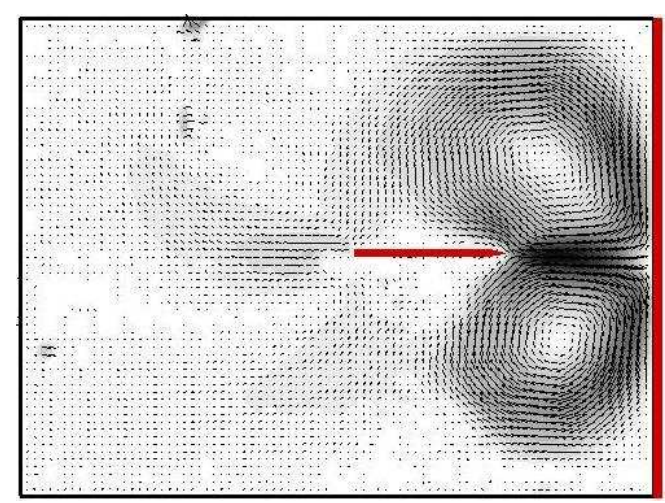

Experiment

Numeric

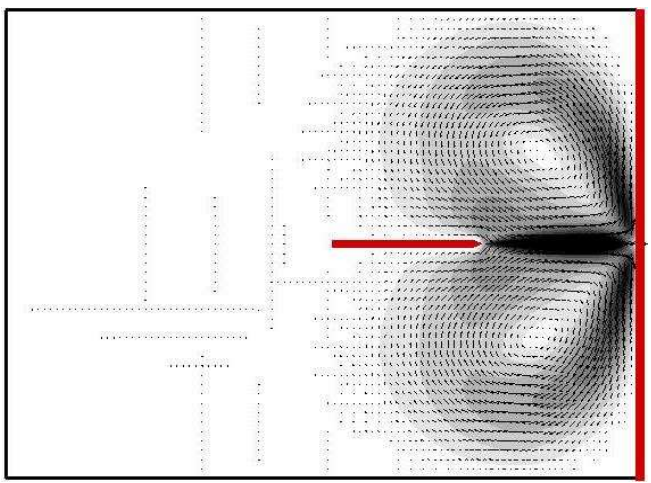

$-20 \mathrm{kV}$
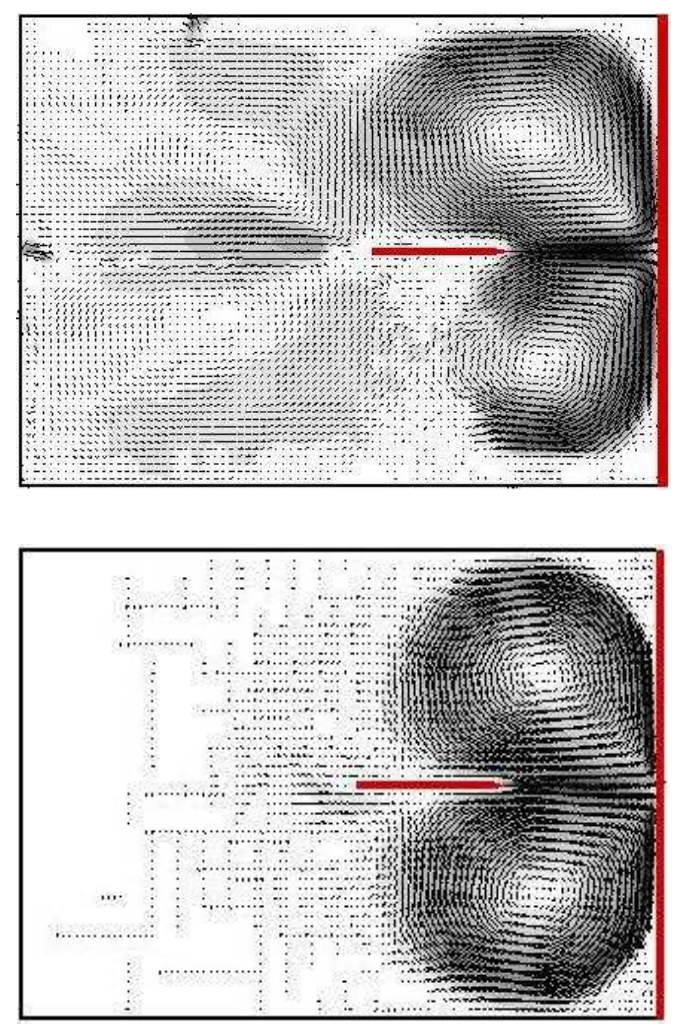

Figure 5. Snapshots of velocity field and isocontours of the velocity magnitude for an applied voltage of $-5 \mathrm{kV}$ and $-20 \mathrm{kV}$

In figure 6 we have plotted the experimental and numerical longitudinal velocity profiles in $\mathrm{x}$ middle plane on the same graph for the both cases $-5 \mathrm{kV}$ and $-20 \mathrm{kV}$. Here again the curves depicted for these two values of the applied voltage match quiet well. The little discrepancy of the profiles is only due to experimental measurements errors as well as a slight dissymmetry of the experimental apparatus that we noticed at the end of our measurements campaign. 

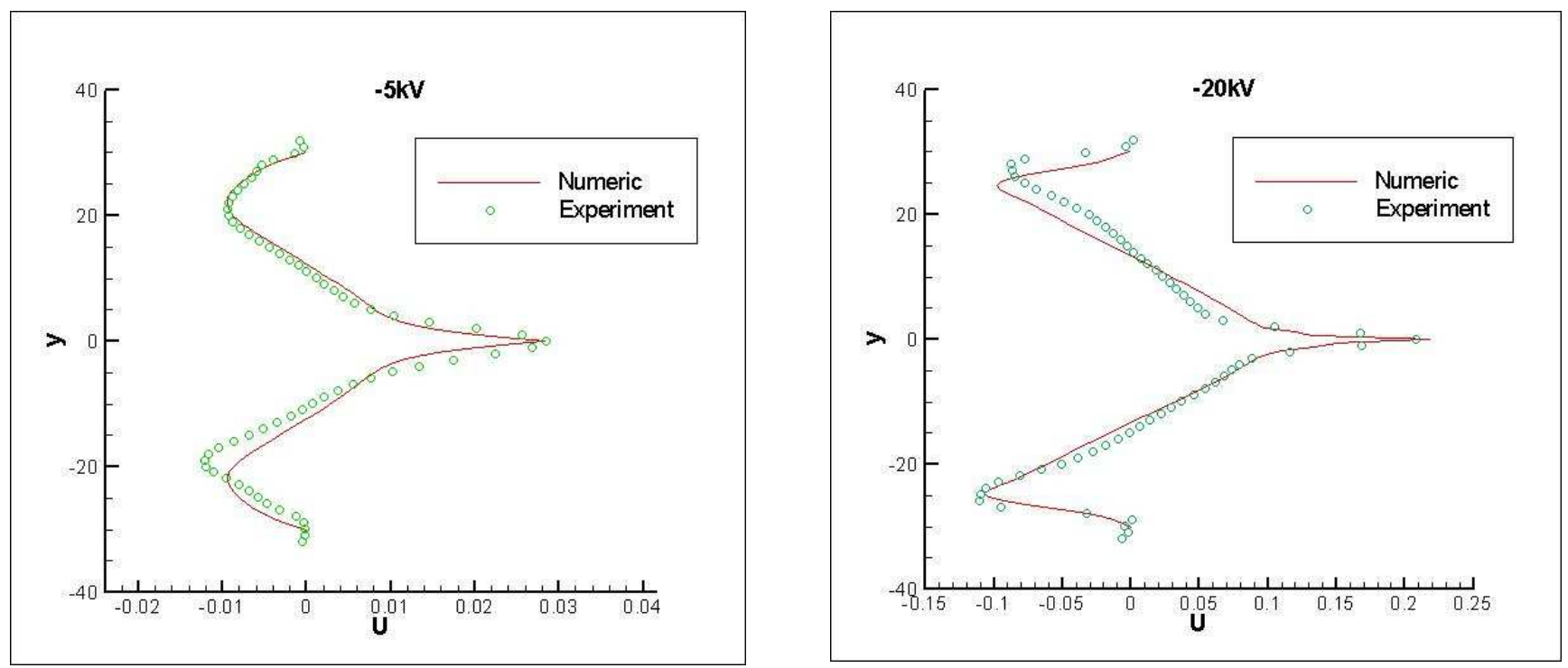

Figure 6. Comparisons of the numerical and experimental longitudinal velocity profiles in the $\mathrm{x}$ middle plane field for two values of the applied voltage.

When we increase the applied voltage from $-5 \mathrm{kV}$ to $-20 \mathrm{kV}$ the flow becomes unsteady and the jet starts to flap. It is sometimes oriented up sometimes down. In figure 7 we have shown two instantaneous numerical and experimental velocity fields which characterize the flapping behavior of the jet flow for $-20 \mathrm{kV}$. This particular effect essentially due to the confinement of the cavity has been already observed in the case of slot jets impinging on a concave curved wall [27] . It is interesting to note that our numerical model is able to reproduce this phenomenon.

Experiment

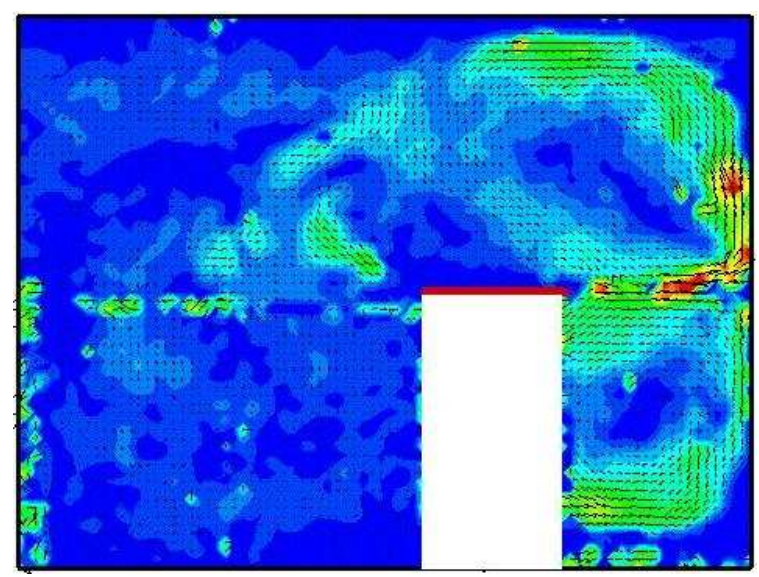

Numeric

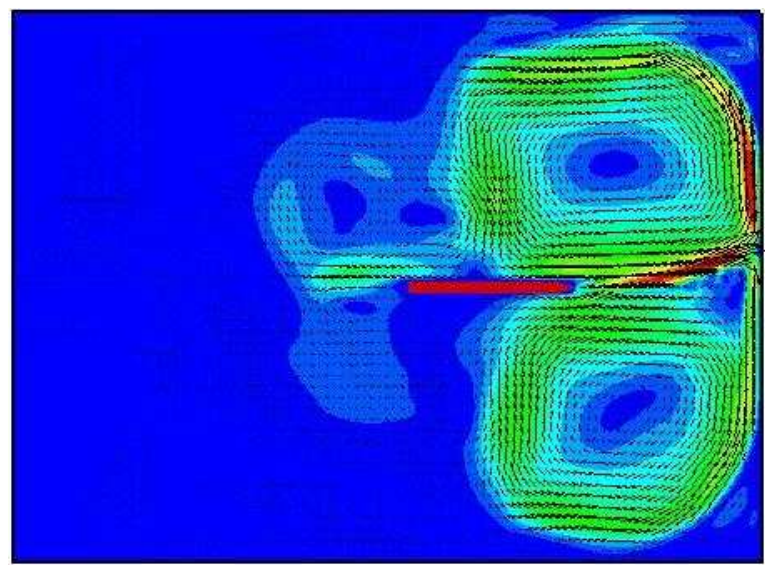



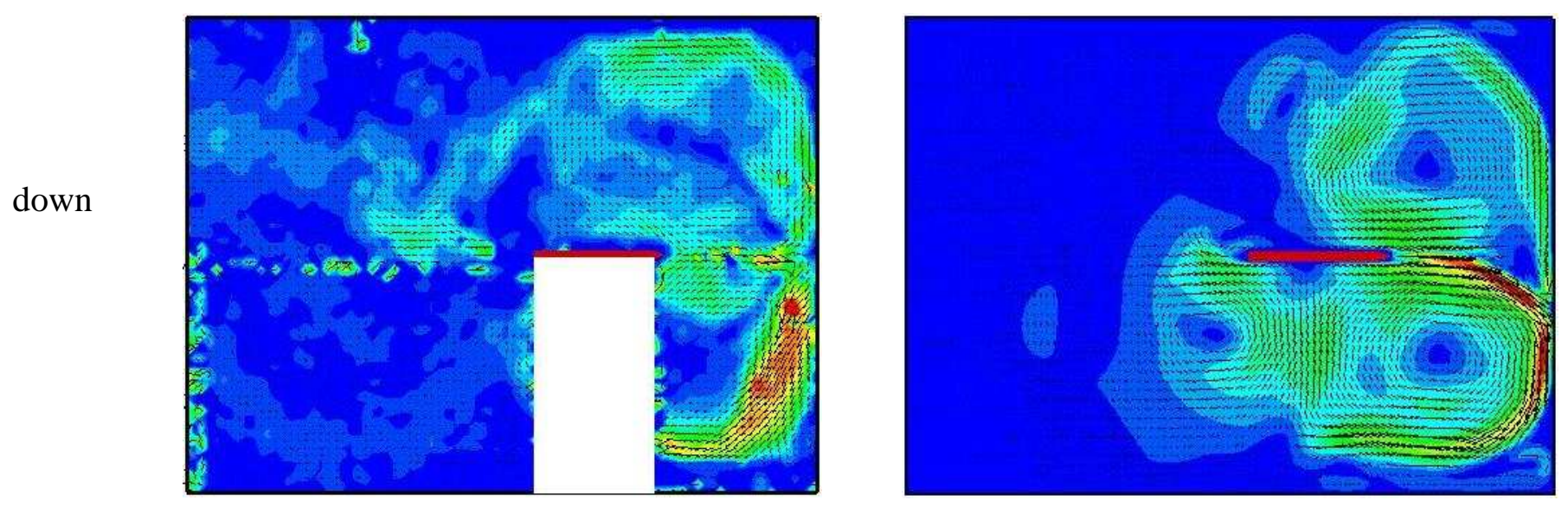

Figure 7. Instantaneous velocity fields and isocontours of the velocity magnitude showing the flapping effect.

Figure 8 presents the contour map of the dimensionless instantaneous pressure field for the two cases considered in this paper, $-5 \mathrm{kV}$ and $-20 \mathrm{kV}$, at the same time of the simulation $t=12.096 \mathrm{~s}$. At this time and for an applied voltage of $-5 \mathrm{kV}$ the steady state is already reached while for $-20 \mathrm{kV}$ the flow remains fully unsteady. It is clearly depicted that the maximum of pressure is logically found on the opposite counter electrode. In the case of $-5 \mathrm{kV}$ the position of this maximum is aligned with the blade electrode on $y=H / 2$ and the flow if fully symmetric. The value of this maximum remains stationary after a short transient period as the flow starts from rest. For $-20 \mathrm{kV}$, the position of this maximum, still located on the opposite wall, varies with time and also along the $y$ axis above or below $y=H / 2$. The flapping effect starts in the early stages of the simulation as it can be seen on figure 9 where the time evolution of the maximum of wall pressure values has been depicted. These fluctuations of the maximum wall pressure are indeed a characteristic of the turbulent behavior of the jet flow for this value of the applied voltage.
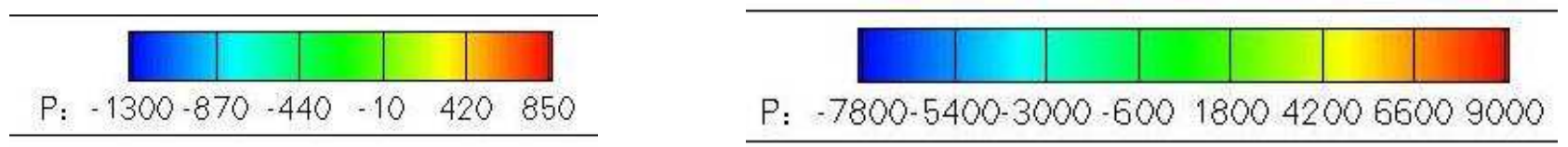

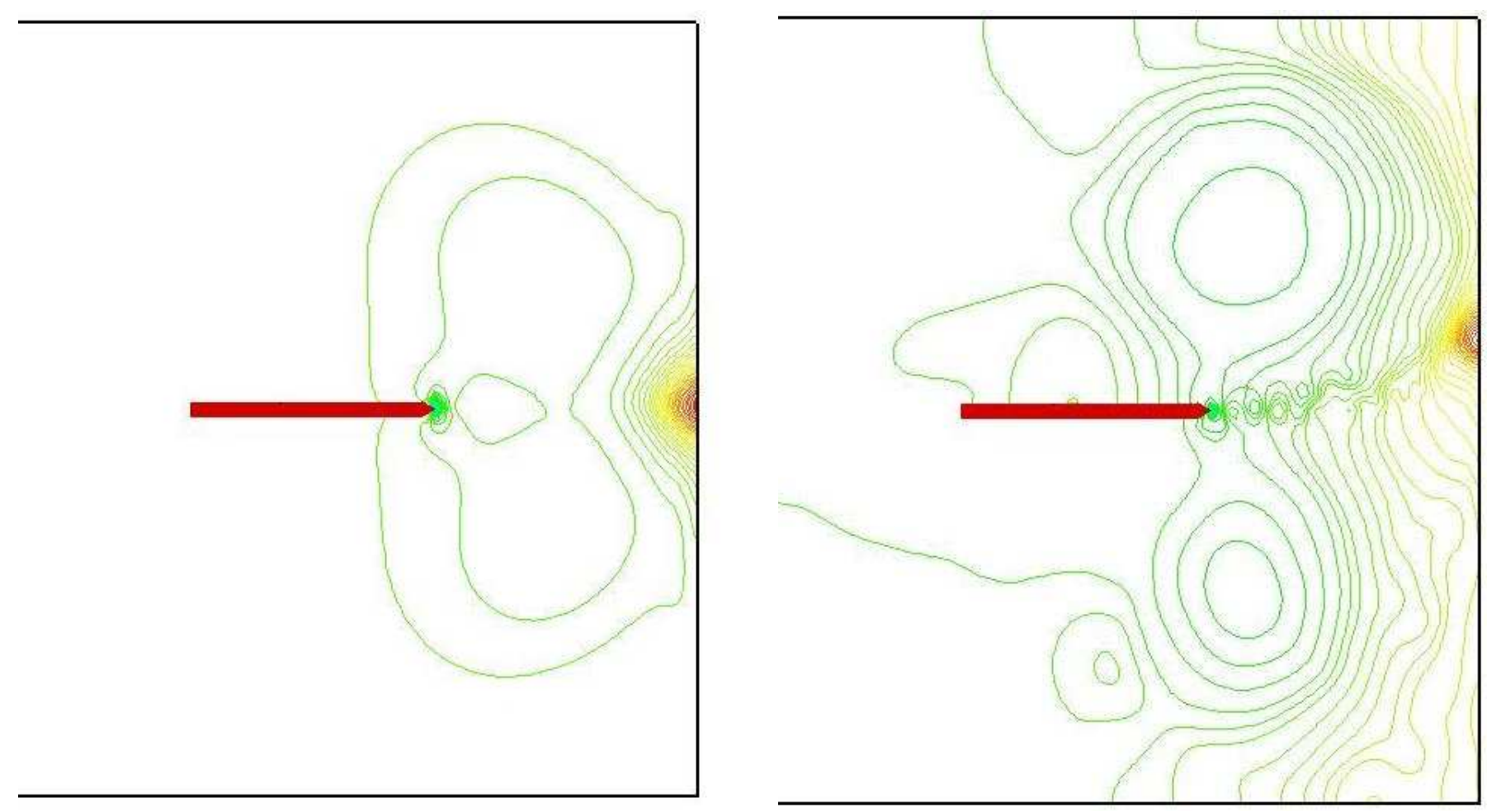

Figure 8..Instantaneous contour map of the dimensionless pressure field.

$-5 \mathrm{kV}$

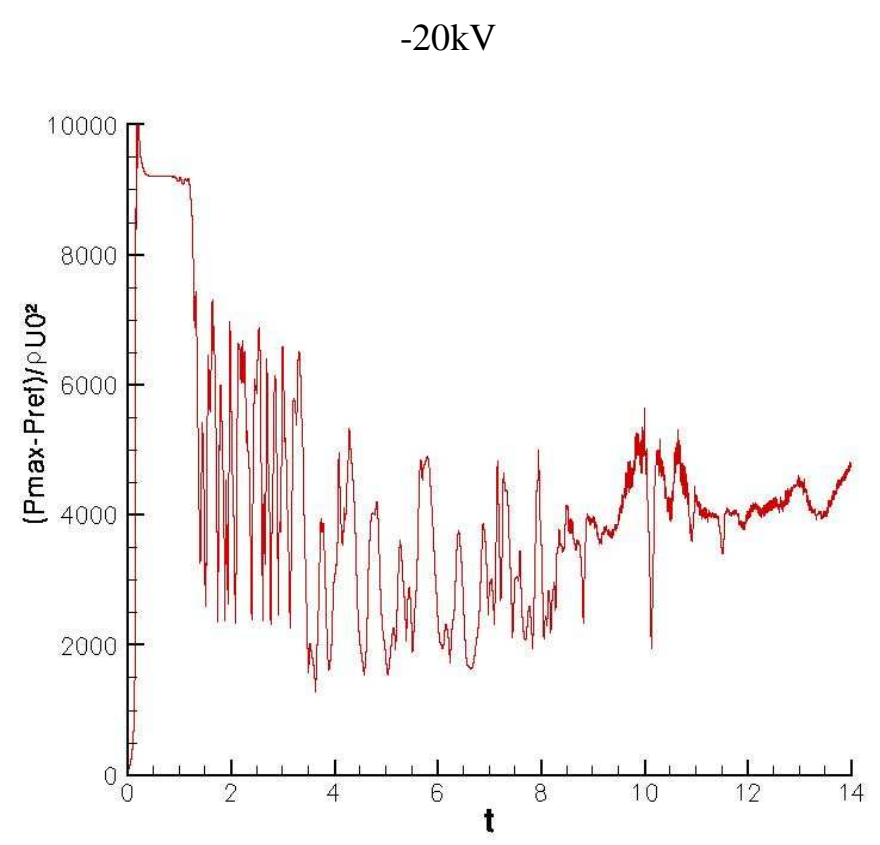

Figure 9. Dimensionless time evolution of the maximum wall pressure. 
One of the most interesting features of numerical simulation is that it allows computing some quantities which are note available by measurements. The charge density is a good example of such inaccessible data by measurement means. In figure 10 we have depicted the time evolution of the dimensionless charge density in the computational domain for an applied voltage of $-5 \mathrm{kV}$. It is interesting to notice that the charge density is confined in a thin layer which arises from the blade until it reaches the counter electrode. The iso-values of this charge density are quite low in accordance with the relatively moderate applied voltage.

\section{Isocontours of the charge density}

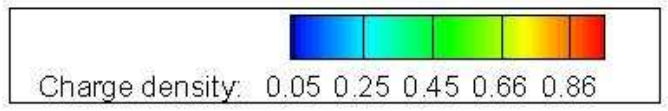

Time

Isocontours of the charge density

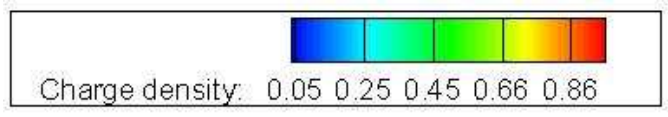

$0.288 \mathrm{~s}$

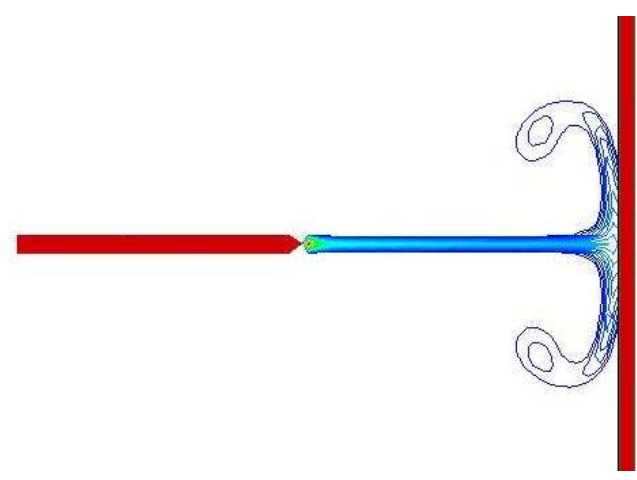

Time

$1.008 \mathrm{~s}$

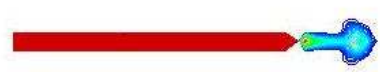

$0.432 \mathrm{~s}$

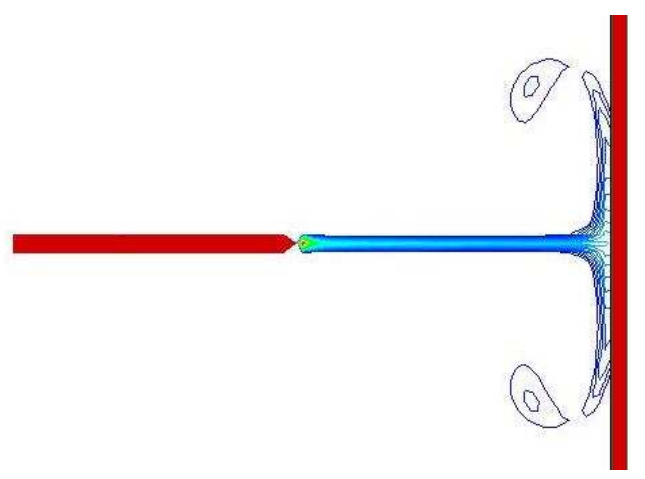



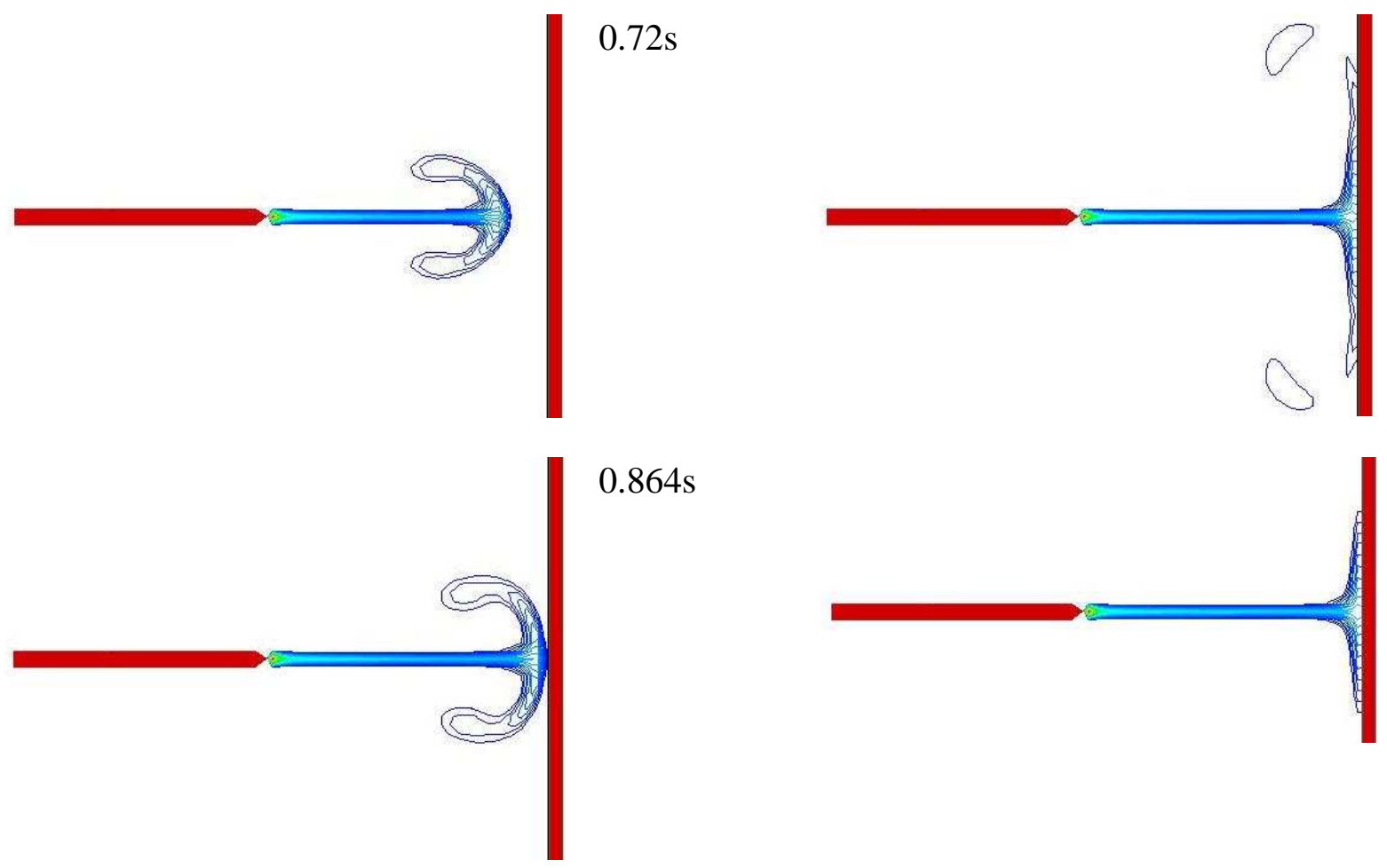

Figure 10. Instantaneous isocontours of the dimensionless charge density at different times of the simulation.

\section{Conclusion}

PIV, experimental measurements and numerical simulations have been conducted to analyze EHD plumes arising from ions injection between a blade and a plane in a dielectric liquid under the influence of an applied voltage. Two cases have been considered: $-5 \mathrm{kV}$ and $-20 \mathrm{kV}$. We have highlighted the existence of a steady and laminar regime for low applied voltage between the blade and the opposite collector electrode. A turbulent regime with the appearance of a flapping effect of the jet flow issued forth from the blade has been observed experimentally as well as numerically for $-20 \mathrm{kV}$ applied voltage.Comparisons between experimental and numerical longitudinal velocity profiles in the $\mathrm{x}$ middle plane, as well as the velocity field for different values of applied voltage show a perfect agreement which testify the validity, capability and efficiency of our numerical model. The use of PIV measurements in the context of EHD flow is a real advance. Nevertheless the real effect of PIV particles in their interactions with flow through their charge catching must be more precisely investigated and determined. 


\section{References}

[1] Chang J.S. "Two phase flow in Electrohydrodynamic" Part V, 1998, Electrohydrodynamics, International center for mechanical sciences courses and lectures, $N^{\circ}$ 380, Castellanos A. (Ed), Springer Wein New-York.

[2] Atten P and Seyed-Yagoobi J 2003, "Electrohydrodynamically induced dielectric liquid flow through pure conduction in point/plane geometry", IEEE Trans. Dielectr. Electr. Insul, Vol. 10, pp. 27-36.

[3] Feng J and Seyed-Yagoobi J 2004, "Understanding of electrohydrodynamic conduction pumping phenomenon", Phys. Fluids, Vol. 16, pp. 2432-2441.

[4] Pearson, M. Seyed-Yagoobi, J. 2009, "Advances in electrohydrodynamic conduction pumping", IEEE Transactions on Dielectrics and Electrical Insulation, Volume: 16, Issue: 2, pp 424-434.

[5] Atten P and Castellanos A 1985, "Injection induced electrohydrodynamic flows", Handbook of Electrostatic Processes, Ed. New York: Dekker, pp. 121-146.

[6] Huigera F J 2000, "Electrohydrodynamic flow of a dielectric liquid around a blade electrode", Phys. Fluids , Vol 12 (11), pp. 2732-2742

[7] Baudel P, Louste C and Romat H 2006, "LDV Measurements of Dielectric Liquid Motion Induced by Charge Injection in a Needle to Plane Configuration," International symposium on Electrohydrodynamics ISEHD/IEEE, pp.149-152, December, Argentina.

[8] Daaboul M, Louste C, and Romat H 2009, "Transient velocity induced by electric injection in blade-plane geometry", J. Electrostatics, Vol. 67, pp. 359-364.

[9] Daaboul M, Louste C, and Romat H 2009, "PIV measurements on charged plumes - Influence of $\mathrm{SiO} 2$ seeding particles on the electrical behavior", IEEE Trans. Dielectr. Electr. Insul., Vol. 16, Issue 2, pp. 335342.

[10] Louste C, Daaboul M, and Romat H 2009, "A study of vortex shedding induced by dielectric barrier injection", J. Electrostatics, Vol. 67, pp. 348-353.

[11] Vazquez P A, Perez A T, Castellanos A, and Atten P 2000, "Dynamics of electrohydrodynamic laminar plumes: Scaling analysis and integral model", Phys. Fluid, Vol 12 (11), pp. 2809-2818.

[12] Vazquez P A, Perez A T and Castellanos A 1996, "Thermal and electrohydrodynamic plumes. A comparative study", Phys. Fluids, Vol 8 (8), pp. 2091-2096.

[13] Vazquez P A, Castellanos A, Perez A T and Chicon R 2000, "Numerical modelling of EHD flows due to injectors of finite size", Conference on Electrical Insulation and Dielectric Phenomena, pp. 101-104.

[14] Vazquez P A, Perez A T and Castellanos A 1996, "Steady and Transcient Electrohydrodynamic Plumes ", Conference on Electrical Insulation and Dielectric Phenomena, IEEE Annual Report, pp. 373-376.

[15] R.Chicon., A. Castellanos, E. Martin 1997, "Numerical modelling of Coulomb-driven convection in insulating liquids", J Fluid Mechanics, 344, pp 43-66.

[16] Perez A T, Traoré Ph, Koulova-Nenova D, and Romat H 2009. "Numerical study of an ElectroHydrodynamic plume between a blade injector and a flat plate", IEEE Transactions on Dielectrics and Electrical Insulation, Vol. 16, pp 448-455.

[17] Atten P, McCluskey F.M.J and Lahjomri A.C, 1987, "The electrohydrodynamic origin of turbulence in electrostatic precipitators", IEEE Trans IAS, Vol IA-23, pp 705-711.

[18] Chang J.-S, Watson A. ,"Electromagnetic hydrodynamics", IEEE Transactions on Dielectrics and Electrical Insulation, Volume 1, Issue 5, October 1994, Pages 871-895.

[19] Yamamoto T., Velkoff, H.R, 1981 ,'Electrohydrodynamics in an electrostatic precipitator", Journal of Fluid Mechanics, Volume 108 ,pp1-18.

[20] Chun, Y.N. Chang, J.-S., Berezin, A.A., Mizeraczyk, 2007, J.," Numerical modeling of near corona wire electrohydrodynamic flow in a wire-plate electrostatic precipitator", IEEE Transactions on Dielectrics and Electrical Insulation, Volume 14 pp. 119-124.

[21] Daaboul M, 2009, "Etude et développements d'actionneurs électrohydrodynamiques pour le controle des écoulements". PhD Thesis, Université de Poitiers, France

[22] Perez A T and Castellanos A, 1989 Physical review A, 40, 5844-5855. 
[23] Vazquez P A, Georghiou G. E. and Castellanos A 2006 Characterization of injection instabilities in electrohydrodynamic by numerical modelling: Comparison of particle in cell and flux corrected transport methods for elctroconvection between two plates. J.Phys. D: Appl. Phys. 39, pp 2754-2763.

[24] Vazquez P A, Georghiou G. E. and Castellanos A 2006 Numerical analysis of the satiability of electrohydrodynamic (EHDi) electroconvection between two plates. J.Phys. D: Appl. Phys. 41, pp 1-10.

[25] Patankar S J 1980, "Numerical Heat Transfer and Fluid Flow", Stockholm, Washington, DC.

[26] Felici N 1972 Direct Current conduction in liquid dielectrics. Part I : A survey of recent progress (Conduction en courant continu dans les liquides diélectriques). Revue générale d'électricité. 2, n 3, pp. 9099

[27] Brizzi L E, Gilard V and Braud P 2006 "Analyse d'un jet plan impactant une paroi concave par PIV classique et rapide", Congrès francophone de techniques laser, CFTL 2006, Toulouse 19-22 Septembre, pp 1-8. 